\title{
African mothers: Raising boys with haemophilia in the UK
}

Nicola Sugg

Disparities in haemophilia care between developed and developing countries persist despite the best efforts of the World Federation of Hemophilia (WFH). With limited availability of and access to coagulation factor concentrates in developing countries, people with haemophilia (PWH) are frequently left prone to lifethreatening bleeds. The experiences that sub- Saharan African mothers face raising a child with haemophilia are challenging. This study explores the difficulties faced by those who have moved to the United Kingdom, as well as their experiences in their countries of origin. Interviews were carried out with four mothers of children diagnosed with severe haemophilia A from Cameroon, the Democratic Republic of Congo, Nigeria and Somalia. Each of these mothers had the same experience of limited or no access to haemophilia care in their countries of origin. On moving to the UK, they experienced feelings of guilt about their ability to access treatment for their sons while others in their families are unable to access treatment. Awareness has been raised by these women and shared with African communities in the UK. In addition, two mothers have engaged in active fundraising in an attempt to establish haemophilia care in their home countries. This adds further to their need for support.

Keywords: African, haemophilia, mother, disease impact, circumcision

Haemophilia is an $\mathrm{x}$-linked bleeding disorder affecting the ability of the blood to clot and to stop bleeding. In its most severe form, factor VIII or IX levels are $<0.01 \mathrm{IU} / \mathrm{ml}$ (normal range, $0.5-1.5 \mathrm{IU} / \mathrm{ml}$ ) and preventive treatment is required in the form of replacement of the deficient coagulation factor VIII (FVIII) or factor IX (FIX). Without treatment those with haemophilia will suffer bleeding into the weightbearing joints, which causes arthritic damage that impairs mobility and the ability to work and gain salary.

Haemophilia A occurs in 1:5,000 male births and haemophilia B occurs in 1:30,000. About two thirds of all children born with haemophilia will have a known family member who has haemophilia. One third of all cases will involve a new genetic mutation, either in the child or in his mother, who may then have subsequent children with haemophilia. Therefore accurate diagnosis is essential to ensure appropriate management $[1,2]$.

In the United Kingdom, 6,778 males were registered with

Nicola Sugg, Great Ormond Street Hospital for Children NHS Foundation Trust, Great Ormond Street, London WC1N 3JH, UK

Email: Nicola.sugg@gosh.nhs.uk

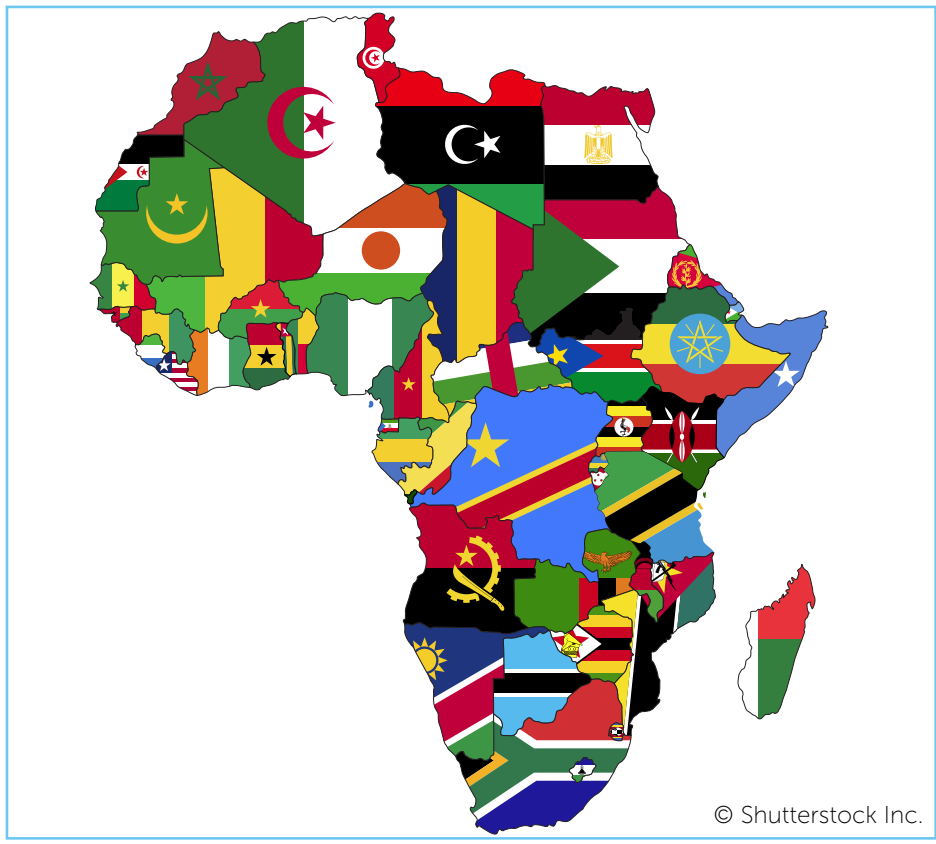

haemophilia in 2013; 5,583 haemophilia A and 1,195 haemophilia B [3]. The NHS funds treatment that is freely accessible to all PWH. Factor VIII usage per capita in the UK is 7.49 IU compared to 0.002 IU in Nigeria, with $1 \mathrm{IU}$ of FVIII/capita being the minimum target to achieve optimal survival for the haemophilia population [4]. To protect joint function or achieve quality of life equivalent to that of a non-haemophiliac higher levels of factor per capita are required [2].

Around $80 \%$ of people with severe haemophilia live in developing countries, with severely limited health resources and so do not receive the same level of treatment as those in developed countries [5]. Because it is a rare disorder, haemophilia is often not seen as a treatment priority by governments. The WFH preference is for treatment with coagulation factor concentrate, but in many developing countries the only available or affordable treatment options involve cryoprecipitate, fresh frozen plasma (FFP), whole blood or plasma. In many African countries coagulation factor concentrate is not available, and governments do not provide treatment for people with haemophilia.

Materials and methods

The research for this study was qualitative and used semistructured open-ended interviews to examine and understand the experiences and views of women from 


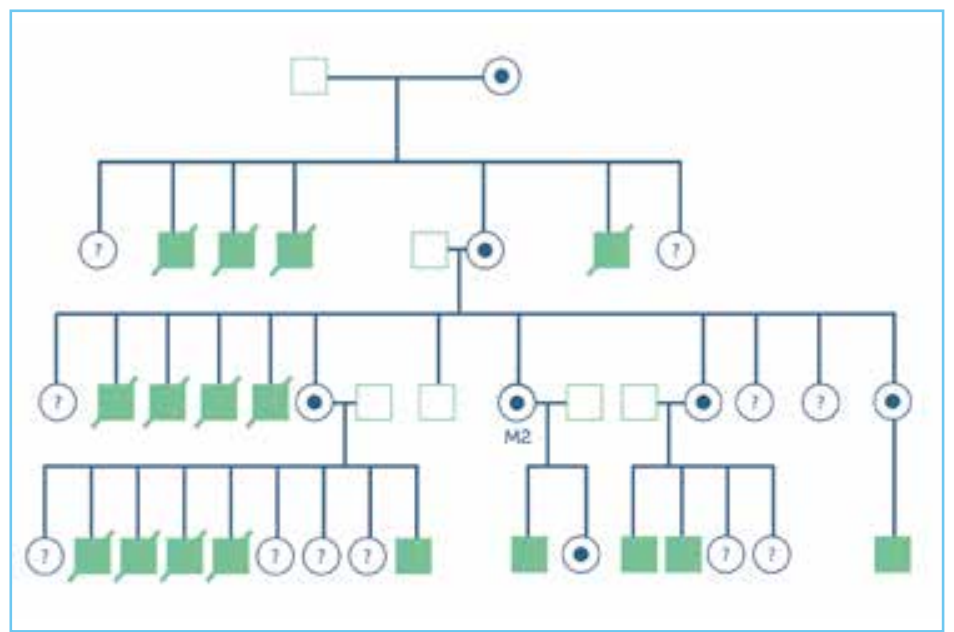

Figure 1: The family tree for $M 2$

Sub-Saharan Africa with sons who have severe haemophilia and are currently treated in London. The women were recruited via the UK Haemophilia Society Afro-Caribbean Women's Group, which offers support to African and Caribbean families. Ethical approval was granted by the University of East London in January 2014. All interviews were undertaken in March 2014 and were digitally recorded, transcribed, analysed and coded. Grounded theory was used to explore themes and newly arising topics were incorporated into subsequent interviews [6]. In this report, participants are anonymised and referred to as Mother 1 (M1), Mother 2 (M2) and so on.

\section{Results}

\section{Patient characteristics}

- Mother 1 (M1), a 33-year-old single mother from Cameroon with no previous family history of haemophilia, migrated to the EU and gave birth to a boy who was diagnosed with severe haemophilia $A$ at 9 months of age. Her understanding of haemophilia prior to her son's diagnosis was limited to what was taught at secondary school studying genetic disease. Following diagnosis she said "there was not much support and I was so scared. It was very scary". In 2010, they moved to London permanently because she felt that treatment was better in the UK.

M1 says she is amazed at her son's understanding of haemophilia. She says that he often says, "Oh mummy medicine makes my haemophilia go away," and "I can go to the gym when I grow up." However, she says that he knows his limitations and understands that there are things he cannot do such as rugby "that is a rough game I cannot do it". In the UK, M1 feels "very independent"; she is able to treat her son everywhere. When asked about the London African community she replied, "I am not really in the African community, partly because I think they wouldn't understand. I've realised that in Africa people are not used to having a condition and when they see somebody with a

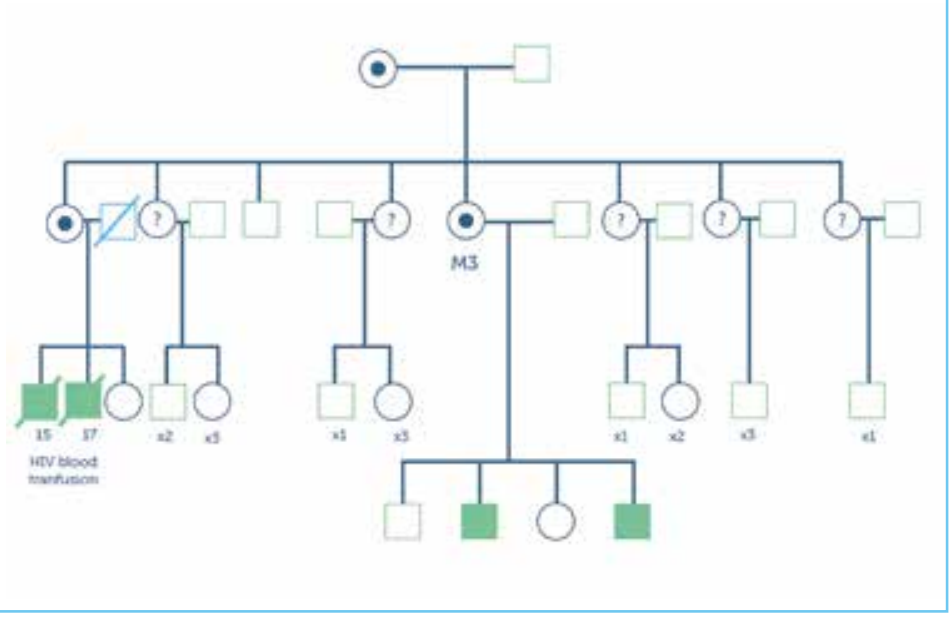

Figure 2: The family tree for M3

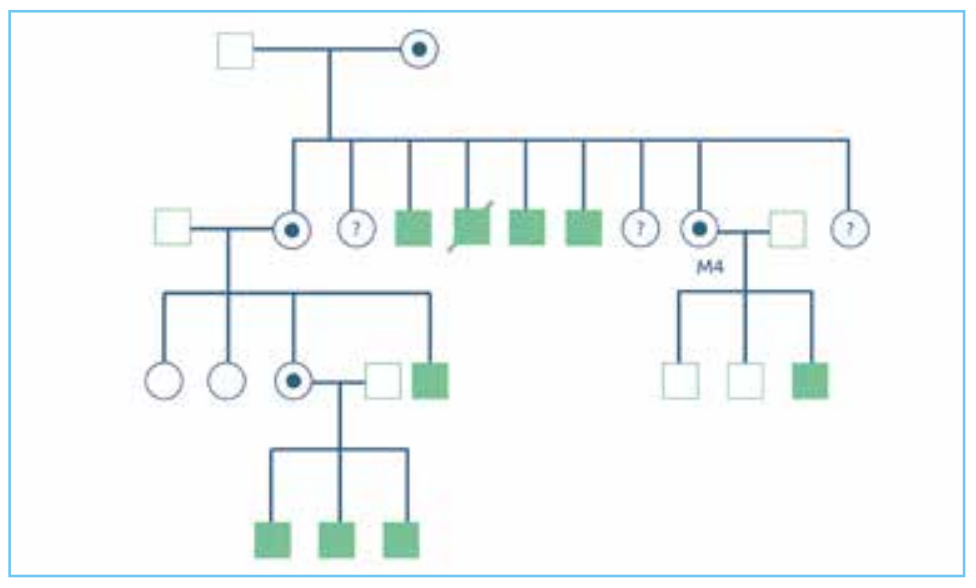

Figure 3: The family tree for M4

condition they have bad attitude, they think the person will die. In Africa his condition, any condition they cannot manage even high blood pressure, so the conditions are normally associated with death not with normal life. I think it makes it harder for Africans to understand when a person has a condition".

M1 has no other family members living in UK and stays here because of her son. "At home he wouldn't have any other support, he wouldn't have financial support, no medication, we don't have anything. I've met haemophiliacs in my country and their life it's really hard, so I'm fortunate enough to be in this country". M1 regularly meets up with other African mothers of boys with haemophilia as part of her support network. "As migrants in a foreign country we have got other issues as well to deal with so when we meet together it's easier, so it's like a family, it's like a second family, so I think basically they are good support."

- Mother 2 (M2) is a 44-year-old married mother with one son and daughter. She originates from the Republic of Congo and migrated to the UK in 1993. She is a carrier of severe haemophilia A and her son was diagnosed at birth 


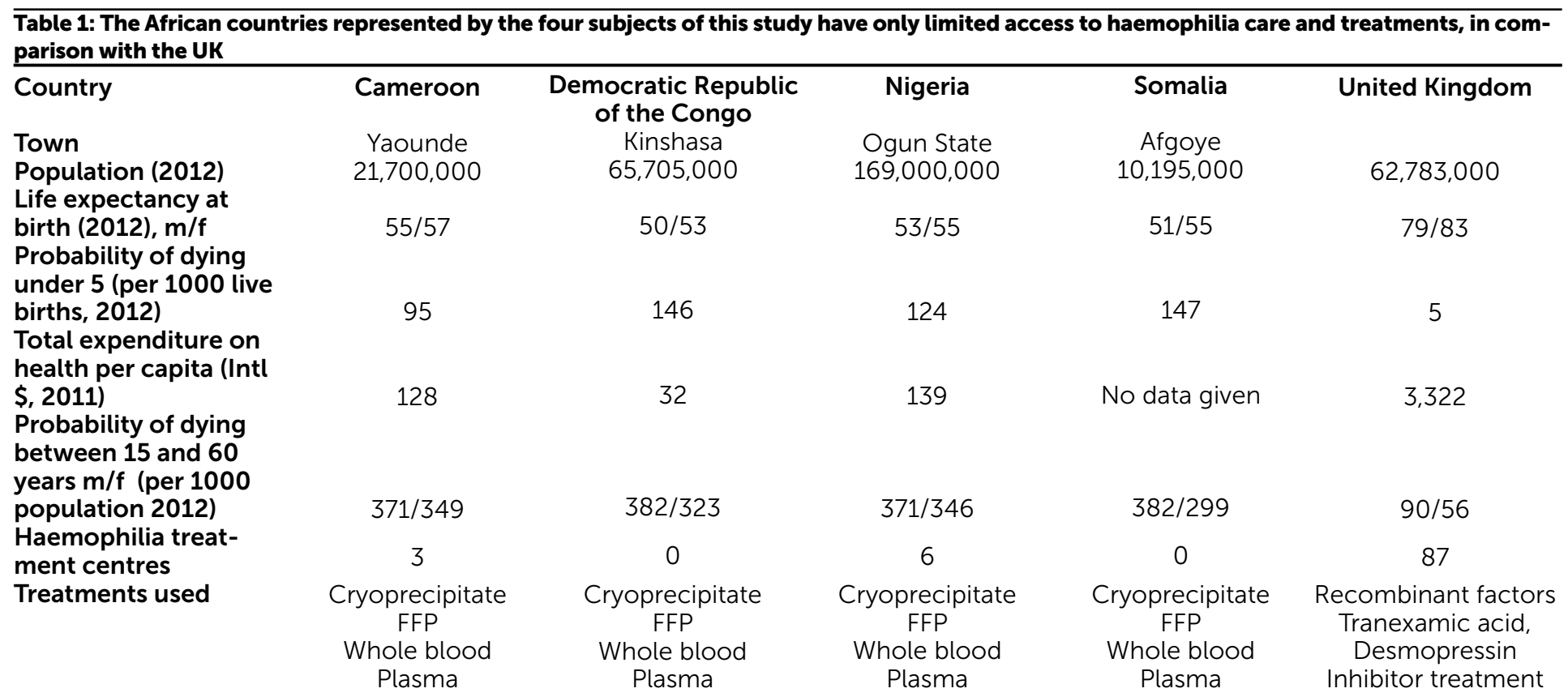

Data from World Health Organization. 2014. Available at: http://www.who.int/countries/cmr/en/;

http://www.who.int/countries/cod/en/; http://www.who.int/countries/nga/en/; http://www.who.int/countries/som/en/;

http://www.who.int/countries/gbr/en/. [All accessed 7 May. 2014]

Data from World Federation of Hemophilia. Global Treatment Centre Directory - World Federation of Hemophilia. 2014. Available at:

http://www.wfh.org/en/page.aspx?pid=1264 [Accessed 1 May. 2014].

in 2000. Her understanding of haemophilia before her son was diagnosed was from her family (Figure 1). "My dad lost four kids before I was born; I have got a sister who's lost four kids as well. We knew that the children were having some bleeding, we didn't know how to treat it. My father knew about it, he knew that it was haemophilia but he didn't know how to deal with it, how to treat it or nothing, no information about haemophilia but he knew that it was haemophilia". Now M2 understands that "it is a missing factor in the blood, a bleeding disorder, some factor VIII or IX is missing". She says her son's understanding of haemophilia is different. "it's difficult you know because you can explain but it's not easy with his age. He will be asking you always question about haemophilia, sometimes he seems to understand a bit, sometimes not much".

On managing the day-to-day aspects of haemophilia, M2 said "sometimes it's a nightmare like for the moment I'm supposed to be at college but when I've got appointment with my son I have to miss, I'm not able to go to do it and I'm thinking sometimes I have to stop going to college have some training and get a job. I don't know sometimes it's too much, I am very lucky having a son in London because if I was having my son in Congo I don't know maybe he should be passed away a long time ago because there is no treatment. A lot of people don't know about haemophilia. Here we've got the best treatment in the world, l'm lucky to be here and having him here and I'm happy in London."

- Mother 3 (M3) is a 41-year-old married mother who moved to the UK in 2005. She has four children (three sons and a daughter), of whom the eldest two sons live in Nigeria. M3 is a carrier of severe haemophilia A, as is her eldest sister who had two affected sons. The eldest died from HIV acquired through blood transfusions (Figure 2). The youngest died from bleeding but was also HIV positive. When asked about her understanding of haemophilia before her UK-born child was diagnosed following a religious circumcision aged two weeks, she said "No idea, I don't have any clue about it at all". However now she comprehends "it's all about blood disorder when the blood doesn't clot properly I am trying to manage but it's not something that is easy. I mean coping with it, it's not really easy because you can't really leave him with another person".

When asked about her experiences compared to those of her sisters she said "my UK son is fine he is $100 \%$ fine, he can do anything but at home it's really really bad. My sister has nothing she has got only one care left [daughter] and she lost everything she had." On discussing haemophilia she said "here children with haemophilia they are $100 \%$ ok. There is no difference in the children and normal children. If I don't tell anyone my son have medical issue they won't know."

- Mother 4 (M4) is a 28-year-old married Somalian mother of three boys, one of whom has haemophilia. M4 has four brothers with haemophilia (the youngest brother died following a chest injury) and five sisters: her elder sister has one son with haemophilia and a daughter, who is a carrier, with three sons with haemophilia (Figure 3). M4's understanding of haemophilia before her son was 
diagnosed was that her brothers had it and her mother had to take them to hospital, "when children fell down or they cut something it doesn't stop bleeding". Now she understands more because "I have got a son he has got haemophilia and I treat him morning and night time two times. I know more than before, now I know lots".

Talking about haemophilia she said "haemophilia is a really bad, bad disease. Sometimes I say I am happy because I got treatment, there are lots of different countries who don't have treatment, here there's lots of people who can help, can explain but if you say 'I've got haemophilia' it's 'how can you got haemophilia you're African I've never saw African got haemophilia'." M4 talked about how she felt about going back to Somalia, seeing affected family members "that makes me scared. I try to send money there because you understand when you have got problems, you know before I did not understand." Her niece has had to relocate to Kenya as the family found it difficult to travel to Kenya on a regular basis when her sons needed treatment "they can go and wait and they treat them but in Somalia they haven't got that at the moment because of the war for 23 years now they haven't got centre to treat haemophilia".

\section{Core themes}

To analyse the transcripts, a thematic approach was used. The transcripts were manually coded and two main themes were identified: circumcision and lack of treatment.

Circumcision: Circumcision is widely practised in African societies for religious, cultural or societal reasons, often undertaken to coincide with naming ceremonies within a couple of weeks of birth [7]. In some families, this is the time at which they realise their baby has haemophilia. In some traditional African ceremonies it is also performed as an initiation ritual and a rite of passage into manhood, where one boy after another is circumcised in traditional male-only ceremonies to mark becoming a man. Boys and their families are pressured to participate in these ceremonies even when they are known to have haemophilia [8]. In this situation, bleeding can be lifethreatening as it is almost impossible to access factor concentrate before or after the ceremony, while to remain uncircumcised may be socially unacceptable [9]. The desire to be circumcised is so strong in African societies that lives are risked having the procedure. In 2010 M3's 2week-old son was diagnosed with severe haemophilia A following a religious circumcision. This allowed a presumptive diagnosis of haemophilia for her older son (who also bled significantly post-circumcision) and her two nephews. M2's youngest sister lives in Angola, her son was circumcised aged 2 months and bled excessively afterwards. M2 said "I asked them to tell the doctor in the hospital that we've got haemophilia in the family, they have to do some test and luckily they did it." M4's youngest son

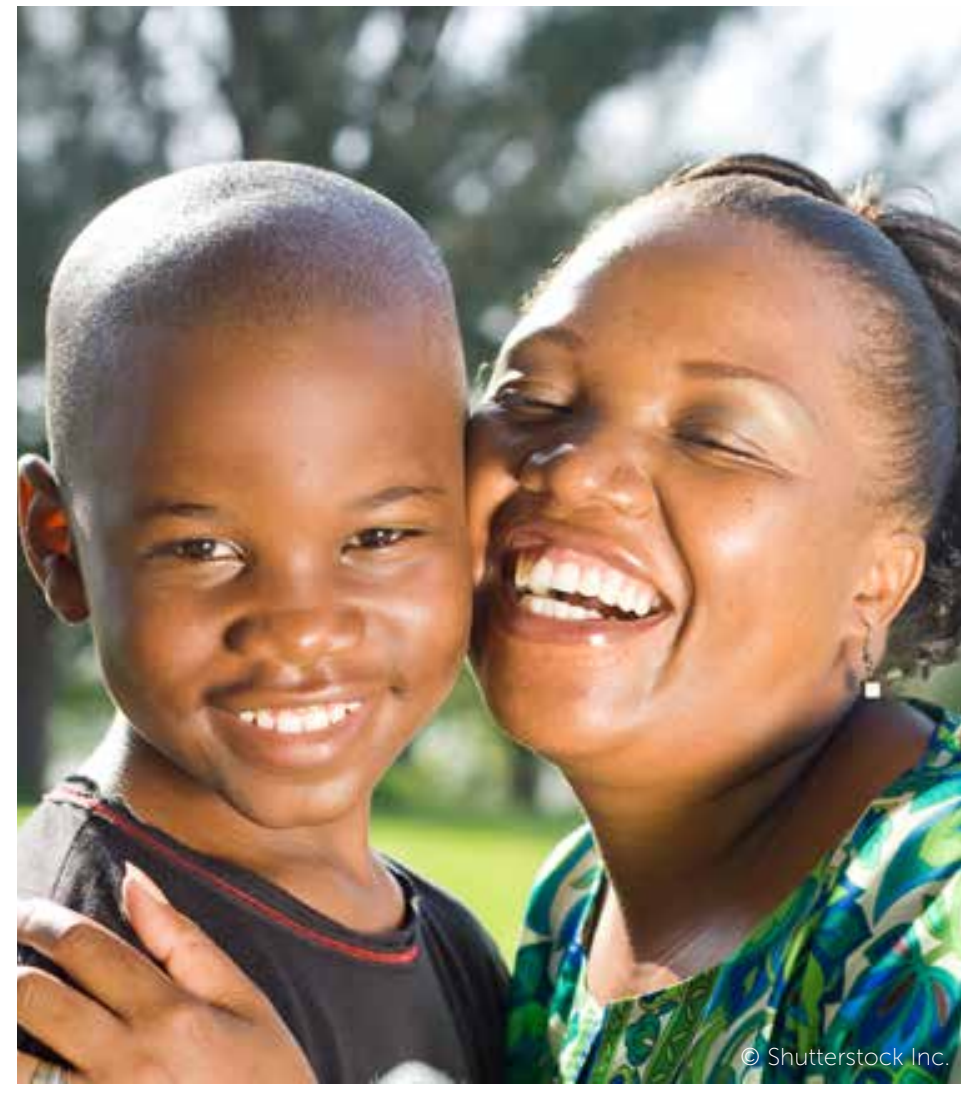

bled for three weeks post-circumcision but was not diagnosed with haemophilia until several months later following swelling and pain in his wrist. M4 said "It's bad, really bad you know, those in my country don't know what is haemophilia, they do a circumcision and that boy he can die as it doesn't stop bleeding like what happened to my son, my brother (who lives in America and has haemophilia) was calling, and he's telling me why do you do that without asking me or others." She did not get her son tested prior to circumcision as "my other two boys they were ok, I was thinking maybe its ok. I just forget and I left it and as they say in Somalia 'that will never happen to me' its ok".

- Lack of treatment: The absence of treatment in developing countries causes much heartache for PWH and their families. Africa is the geographical area most underrepresented by the WFH [10], with disparities across this region (Table 1). Affordable, safe factor concentrate is rarely available. Treatment with donated blood products, cryoprecipitate or FFP are often the only therapeutic options available.

M2 said of her family in Congo: "They don't have any factor back home. What they have there is only blood transfusion, that's the only thing there've got and when they've got a bleeding I have to tell them to use the ice pack, how to position the leg or the arm." She has two nephews with damaged joints, which make walking difficult. Although the medical staff understand the condition, they have no treatment to offer. On seeing how 
her experience influences her family's understanding of haemophilia she said, "by explaining them what to do in case their sons got bleeding, I can't help them with the factor but just explain to them what to do and keep calling them, find out everything". She said that living with haemophilia in the UK is easier for her than for family members at home, "I can manage if I've got a problem, I can phone the hospital or come to the hospital straightaway but back home it's different, they don't have haemophilia centre, it's hard for them to get access to the factor, there is no factor back home".

When asked about living in the UK M3 said, "it's better here. With the experiences my sister's got it's a lot of difference. Its 100\% difference because she got two sons with haemophilia and both of them are no more, one died at the age of 17 years and he has been to the hospital throughout his life on every week and unfortunately he was given HIV blood. My sister lost this boy, almost five years [ago]. Then the second one about two or three years ago died at the age of at 15 years he had HIV, there is no treatment for him."

When talking about having haemophilia in the UK compared to Nigeria M3 said, "It's very good compared to Nigeria. My son over there he's really facing difficulties ... at times he can go to school, somebody push him when he was at school [he banged his head]. They took him to the hospital, [the] doctor couldn't attend to him, this boy was really bleeding and they couldn't attend to him. He had been taking lots of blood products, I have to stop it, because I was warned don't give this boy any blood, It makes me feel bad because anytime they call me from Nigeria I am really scared."

Recently she received a call regarding her son in Nigeria. "They have to rush him to the hospital, I have to talk to them because he was bleeding so I ask them at the general hospital that they should give him the factor instead of blood, they should give him that factor because I have a son here that has the same medical issue and this is the treatment we give him here and his blood is fine, the doctor said they can't give the factor, he don't know anything about it. Blood was rushing like tap, the blood was rushing rushing rushing and they stitch, do the stitching more than three times. They have to take him back to the hospital maybe after three days because it don't work, not stop, they wrapped it. Talking to the doctor please give him the factor then this boy will be fine, I don't want you to give him blood, don't give any more this blood it's too much, if anything happens I am responsible, I am the mum."

M4 spoke about her experience of living with haemophilia in the UK compared to that of her family members in Somalia. "They've got medicine it's fine here, but in my country it's difficult really. Where we live and where the hospital is 45 kilometres and sometimes my mum she hasn't got enough money to go to the hospital but here it's easy enough to go". She went on to say that

\section{Four elements of the right to health}

\section{Availability}

A sufficient quantity of functioning public health and health care facilities, goods and services, as well as programmes.

\section{Accessibility}

Health facilities, goods and services accessible to everyone. Accessibility has four overlapping dimensions:

non-discrimination

physical accessibility

economical accessibility (affordability)

information accessibility.

\section{Acceptability}

All health facilities, goods and services must be respectful of medical ethics and culturally appropriate as well as sensitive to gender and life-cycle requirements.

\section{Quality}

Health facilities, goods and services must be scientifically and medically appropriate and of good quality.

Source: www.who.int/mediacentre/factsheets/fs323/en/

while there was some treatment for haemophilia in Somalia before the war now it was difficult. Her niece has three boys with haemophilia and travelled to Nairobi in Kenya "by car for eight days and eight nights" to receive treatment. They have since migrated to Kenya as the journey was too difficult.

M4 said that treatment in Somalia involved little more than painkillers. "My brother I remember he was crying, he's dead now really l'm sorry about him, he was crying a lot from night time even day time but he was just given painkiller or a bag of ice. My sister was giving him her blood, we don't know what else to do my sister she went to Italy and that's why no one given him more blood and he died."

\section{Discussion}

Structural violence is one way of describing social arrangements that put individuals and populations in harm's way [11]. Structural violence disadvantages individuals, as is evident in Somalia, where two decades of war has left its people experiencing violence, lawlessness, worsening poverty and health. The impact of structural violence is seen in the world's poorest countries, where it has extreme implications for those seeking to provide clinical services. For those living with haemophilia in Somalia, as in much of Africa, there is no haemophilia care and families have to travel in an attempt to receive treatment, even when there is no guaranteed access to treatment.

The World Health Organization constitution enshrines the highest attainable standard of health as a fundamental right of every human being. The right to health does not 


\section{The AAAQ of the health workforce}

\section{Availability}

The sufficient supply and appropriate stock of health workers, with the competencies and skill-mix to match the health needs of the population.

\section{Accessibility}

The equitable distribution of these health workers taking into account the demographic composition, rural-urban mix and under-served areas or populations.

\section{Acceptability}

Health workforce characteristics and ability (e.g. sex, language, culture, age, etc.) to treat all patients with dignity, create trust and promote demand for services.

\section{Quality}

Health workforce competencies, skills, knowledge and behaviour, as assessed according to professional norms and as perceived by users.

http://www.who.int/workforcealliance/media/qa/04/en/

mean the right to be healthy, rather it means that governments must generate conditions in which every person can be as healthy as possible, with access to timely, acceptable, and affordable health care of appropriate quality $[12,13]$. Numerous national constitutions along with regional and international human rights treaties have adopted WHO's AAAQ framework, which identifies availability, accessibility, acceptability and quality of health care facilities as essential elements of the right to health (see panel). The framework extends to the underlying determinants of health and also covers access to health care and treatment, yet this is not available to those with haemophilia in most African countries [12]. WFH guidelines for the management of haemophilia include general care, specialist management issues, laboratory diagnosis and treatment [2]. However, in Africa, the lack of multidisciplinary teams, inaccessible comprehensive care centres, inappropriate medical facilities and suboptimal quality of care leads to poor health outcomes or death for people with haemophilia and their families.

Haemophilia is a neglected disease in most developing countries, where people living in poverty perceive health as the only asset on which they can rely. Health is a basic human right and access to minimal levels of essential drugs and health services are fundamental, therefore the human rights of people with haemophilia are being violated. The human right to health means that hospitals, clinics and medicines should promote universal affordable comprehensive care, which should be physically and economically accessible to all members of society. The health infrastructure should provide goods (equipment, medicines and so on) and services (including sexual health and mental health) in all areas in all communities. Acceptability and dignity should be respected, health information and education must be promoted in easily accessible formats to enable people to protect their health and maintain good quality of life. The infrastructure needed to care for people with haemophilia in developing countries is still trailing behind that of the developed world but the hope is that one day treatment will be available for those with haemophilia regardless of where they live.

\section{Conclusion}

The disparities in haemophilia care between developed and developing countries continue to exist despite work by the WFH and international policy makers $[14,15]$. Progress is being made, yet even in those African countries where war is no longer an issue, haemophilia care lags behind due to the enormous costs to improve one person's life; this is understandable when compared to the impact of treatment for infectious diseases. For those with haemophilia, health inequalities remain a major concern and will continue to impact on migration from countries where there is little or no treatment to those where there is treatment available. For some families this may mean leaving the African continent for Western countries. This has immediate positive impacts on life for the individual with access to treatment but also has detrimental impacts in that families are left behind and family support may be lost. Thus haemophilia is a force for separation of families due to limited access to treatment.

\section{Disclosures}

This author has advised that she has no interests that might be perceived as posing a conflict or bias.

\section{References}

1. Jayandharan GR, Srivastava A, Srivastava A. Role of molecular genetics in hemophilia: from diagnosis to therapy. Semin Thromb Hemost 2012; 38X1Y: 64W78. doi: 10.1055/sW0031W1300953

2. Srivastava A, Brewer AK, MauserWBunschoten EP, et al. Guidelines for the management of hemophilia. Haemophilia 2013; 19X1Y: e1W47. doi: 10.1111/j.1365W 2516.2012.02909.x.

3. UKHCDO Annual Report 2013 \& Bleeding Disorders Statistics for the Financial Year 2012/2013. 2013. Zreport[ p. 6.

4. O'Mahony B, Noone D, Giangrande PL, Prihodova L. Haemophilia care in Europea survey of 35 countries. Haemophilia 2013; 19X4Y: e239W47. doi: 10.1111/hae.12125. 5. De Kleijn P, Odent T, Berntorp E, et al. Differences between developed and developing countries in paediatric care in haemophilia. Haemophilia 2012; 18 Suppl 4: 94W100. doi: 10.1111/j.1365W2516.2012.02875.x.

6. Bedford M. An introduction to grounded theory. J Haem Pract 2014; 1X1Y: 8W9. doi: $10.17225 /$ jhp.00004

7. Shittu OB, Shokunbi WA. Circumcision in haemophiliacs: the Nigerian experience. Haemophilia 2001; 7: 5341536.

8. Tazi I. Circumcision and haemophilia in developing countries. East Afr J Public Health 2009; 6X3Y 334.

9. Zulfikar B, Karaman MI, Ovali F. Circumcision in Hemophilia: An Overview. 2003. Zonline[ Available at: http://www1.wfh.org/publication/files/pdfW1170.pdf

10. Skinner MW. Building our global family \achieving treatment for all.

Haemophilia 2010; 16 Suppl 5: 1W10. doi: 10.1111/j.1365W2516.2010.02285.x 11. Farmer PE, Nizeye B, Stulac S, Keshavjee S. Structural violence and clinical medicine. PLoS Med 2006; 3X10Y: e449. Available at:

http://www.ncbi.nlm.nih.gov/pmc/articles/PMC1621099/pdf/pmed.0030449.pdf 12. World Health Organization in South East Asia. The right to health. 2014. Available at: http://www.searo.who.int/entity/human_rights/topics/right_to_health/en/ 13. World Health Organization. The right to health. 2014. Available at: http://www.who.int/mediacentre/factsheets/fs323/en/

14. World Federation of Hemophilia. Global Alliance for Progress XGAPY W World Federation of Hemophilia. 2013. Available at:

http://www wfh.org/en/page.aspx?pid=814

15. World Federation of Hemophilia. Cosing the Gap W Campaign Bulletin

December 2013, No. 5. Available at: http://www1.wfh.org/publications/files/pdfw 1572.pdf 